\title{
Significado de la docencia y procesos formativos del profesorado en el área de la salud: Los inicios en la docencia
}

\author{
Meaning of Teaching and Formative Processes of Teachers in the Area of Health: \\ The Beginning of Teaching
}

\section{Significado do ensino e processos de formação de professores na área da saúde: o início do ensino}

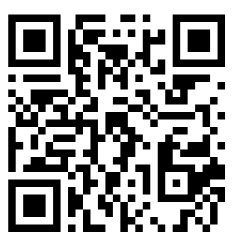

Elí Orlando Lozano-González Universidad Nacional Autónoma de México Facultad de Estudios Superiores Iztacala

Ciudad de México, México eli.orlando.lozano@gmail.com https://orcid.org/0000-0001-9858-0987

Recibido • Received • Recebido: 21 / 09 / 2018

Corregido • Revised • Revisado: 13 / 08 / 2019

Aceptado • Accepted $\cdot$ Aprovado: $13 / 11 / 2019$

\begin{abstract}
Resumen: Más allá de los procesos de capacitación, actualización, entrenamiento o escolaridad, el profesorado del área de la salud comienza su proceso de formación docente en el momento en que se asume como tal; ya no solo como profesionales de la salud, sino de la enseñanza. En este sentido, sus procesos formativos como docentes se vinculan con el significado que le dan a la docencia. Este artículo explora los significados que el profesorado de la Facultad de Estudios Superiores Iztacala de la Universidad Nacional Autónoma de México le da a la docencia, para analizar, con base en ello, sus procesos formativos. Se trata de una investigación de corte cualitativo que contó con la participación de 38 docentes del área de la salud y la biología que contestaron 2 preguntas de tipo narrativo: ¿qué significa para mí ser docente? y ¿cómo llegué a ser docente? Las respuestas se agrupan en tres categorías respecto al significado que le otorgan a la docencia: la primera refiere a su acción sobre el alumnado, la segunda al compromiso y responsabilidad que implica la labor docente y la tercera a un sentimiento de orgullo y satisfacción de desempañarse en labores de enseñanza. Quienes significan la docencia en la segunda o tercera categoría se han asumido a sí mismos o a sí mismas como docentes; por ello se encuentran en proceso formativo, buscan transformarse constantemente en su labor de enseñanza. Enseñar ya no es solo un trabajo, es una forma de vida.
\end{abstract}

Palabras claves: Área de la salud; docencia; formación de profesorado; significado; nivel superior. 
doi: http://doi.org/10.15359/ree.24-1.14

URL: http://www.una.ac.cr/educare

CORREO: educare@una.cr

\begin{abstract}
Beyond the processes of training, updating, or schooling, the teachers of the health area begin their processes of the formation when they assume themselves as such; no longer just health professionals, but teaching professionals. In this sense, their formative processes as teachers are linked to the meaning they give to teaching. For the article to analyze their formative processes based on this, it explores the meanings that the professors of the Iztacala Higher Studies School of the National Autonomous University of Mexico give to teaching. This paper is a qualitative research design that included the participation of 38 teachers from the health and biology area; they answered two questions of a narrative type: What does it mean for me to be a teacher? How did I become a teacher? The answers are grouped into three categories concerning the meaning they give to teaching. The first category refers to its action on the students. The second one, to the commitment and responsibility implied in the teaching work. And the third one, to a feeling of pride and satisfaction of carrying out teaching tasks. Teachers who mean teaching in the second or third category have assumed themselves as such; for this reason, they are in a formative process, they seek to transform themselves continually in their teaching work. Teaching is no longer just a job; it is a way of life.
\end{abstract}

Keywords: Area of health, formation, teacher formation, meaning, higher level.

Resumo: Além dos processos de treinamento, atualização, capacitação ou escolaridade, os professores da área da saúde iniciam seu processo de formação de professores no momento em que é assumido como tal; não apenas como profissionais de saúde, mas também como professores. Nesse sentido, seus processos de formação como professores estão ligados ao significado que atribuem ao ensino. Este artigo explora os significados que o corpo docente da Faculdade de Estudos Superiores de Iztacala da Universidade Nacional Autônoma do México atribui ao ensino, para, com esta base, analisar seus processos de formação. Trata-se de uma pesquisa qualitativa que contou com a participação de 38 professores da área de saúde e biologia, convidados a responder a 2 questões de tipo narrativa: o que significa para mim ser professor? E como me tornei professor? As respostas estão agrupadas em três categorias, quanto ao significado que atribuem ao ensino: a primeira se refere à ação que exercem sobre os alunos, a segunda se refere ao compromisso e à responsabilidade implícita no trabalho docente e a terceira ao sentimento de orgulho e satisfação do desempenho de seu trabalho como professor. Para aqueles que encontram significado no ensino na segunda ou terceira categoria se assumem como professores; Portanto, eles estão em um processo formativo, buscando transformar-se constantemente em seu trabalho como professor. Ensinar não é mais apenas um trabalho, é um modo de vida.

Palavras-chave: Área de saúde; ensino; formação de professores; significado; nível superior.

\title{
Introducción
}

Este artículo es resultado del trabajo en el proyecto de investigación registrado con el número IA401317 y título "Cultura y Formación Docente en la Facultad de Estudios Superiores (FES) Iztacala" con financiamiento del Programa de Apoyo a Proyectos de Investigación e Innovación Tecnológica (PAPIIT) de la Dirección General de Asuntos del Personal Académico (DGAPA) de la Universidad Nacional Autónoma de México (UNAM) (UNAM, 2017). La investigación toma como escenario la FES Iztacala, espacio universitario enfocado en el área de la salud y la biología, en esta facultad se imparten las licenciaturas de Enfermería, Médico Cirujano, Cirujano Dentista, Psicología, Optometría y Biología. 
La mayoría del profesorado que aquí labora tiene un denominador en común: inicialmente no fue preparado profesionalmente para despeñarse en labores de docencia, es egresado de las mismas carreras que antes se mencionaron; sin embargo, actualmente ejercen como docentes. El profesorado de esta facultad se integra a esta por diversas circunstancias; en ocasiones es un anhelo que persiguen y finalmente consiguen, en otros casos es por necesidad económica o también por casualidad. Una vez en sus labores docentes, parte del profesorado de la FES Iztacala cursa posgrados, cursos, talleres o diplomados en áreas de la pedagogía, la educación, la didáctica o la docencia; hay otro grupo que no. Todo ello es parte de su formación como docentes, pero parto de la premisa de que la formación docente es un proceso que va más allá de la escolaridad y la capacitación o entrenamiento. La formación inicia cuando la persona se asume a sí misma en proceso de formación, para ello debe reconocerse como parte de aquello en lo que se forma. Si hablamos de la formación docente del profesorado en el área de la salud, esto implica que dicho profesorado se asume a sí mismo como docentes (al igual que se asumen profesionales de la medicina, odontología, enfermería, biología, etc.), y adquiere responsabilidad sobre su trayecto formativo en la docencia.

Lo anterior remite al significado que el profesorado tiene respecto a la docencia. Los significados se construyen con base en las experiencias y las interacciones en los mundos sociales donde los sujetos se desenvuelven cotidianamente; son también orientaciones para la acción, dependiendo del significado que el profesorado tenga respecto a la docencia es la manera en que actúa día a día en su práctica docente. Por ello, el significado que el profesorado en el área de la salud le da a la docencia es un importante elemento a considerar en el estudio de sus procesos formativos.

Este artículo es resultado del análisis de testimonios de docentes de la FES Iztacala en torno a los significados que le dan a la docencia y la relación que tienen con sus trayectos formativos, específicamente con sus inicios en la docencia. Se presentan algunos testimonios y se interpretan a la luz que otorgan las bases teóricas que sustentan esta investigación. Por ello, se inicia con una discusión en torno a lo presentado en los párrafos previos, se brinda un sustento teórico a las ideas hasta ahora manejadas; posteriormente se describe el proceso metodológico que se siguió para la recolección y análisis de los testimonios y, con ello, se da pie a la presentación e interpretación de estos mismos.

\section{En torno al concepto de formación docente}

Antes de hablar específicamente acerca de la formación docente, es preciso enfocarse en el concepto de formación de una manera más amplia. En la actualidad existe una clara asociación entre el concepto de formación y otros similares, pero no iguales, tales como escolaridad, capacitación, adiestramiento, entrenamiento y profesionalización (todos son procesos que se pueden certificar). Comúnmente se habla de formación y esto remite a pensar en los grados 
doi: http://doi.org/10.15359/ree.24-1.14

URL: http://www.una.ac.cr/educare

CORREO: educare@una.cr

académicos, en los cursos, diplomados o talleres que determinada persona ha tomado en relación con cierta materia; así, es posible afirmar que dicha persona ha sido formada y tiene documentos que lo prueban, su formación está certificada. En este artículo no pretendo negar ni demeritar la dimensión certificable de la formación, pero sí afirmo que la formación es mucho más que la escolaridad, la capacitación o cualquier proceso que se pueda certificar. Es un proceso que sucede en la vida cotidiana de las personas, que implica reflexionar y transformar aquello en lo que se forma. El trayecto formativo se asume como algo personal y de lo que se está consciente.

Entiendo, también, que el concepto de formación es polisémico y complejo, existen diversas nociones y perspectivas teóricas y filosóficas para entender y definir la formación. Pero en la construcción realizada en esta investigación se entiende que la formación refiere al proceso mediante el cual las personas se apropian de cierta cultura y la construyen (Ducoing y Fortoul, 2013; Gadamer, 2012; Hegel, 1984; Honoré, 1980; Yurén, 1999).

Hegel (1984) menciona que el ser humano, inserto en la cultura y la sociedad, requiere formarse. Se habla así de formación cultural, se trata del acceso a la cultura. La formación es, en primer lugar, la adquisición de cierta cultura para dominar la propia naturaleza. Gadamer (2012) apunta que la formación va más allá de las conductas, habilidades y destrezas, y, por tanto, del desarrollo de capacidades o talentos; considera que en la formación es trabajo y transformación del sujeto sobre sí mismo y de la cultura, en este proceso "uno se apropia por entero aquello en lo cual y a través de lo cual uno se forma. ... En la formación alcanzada nada desaparece, sino que todo se guarda" (p. 40). La formación es transformación del individuo y de la cultura.

De acuerdo con Honoré (1980), la formación implica salirse del espacio de confort, enfrentarse a otros escenarios y sujetos que confrontan nuestras prácticas. Es una actividad compleja que requiere un conocimiento progresivo de la realidad que se da en la relación con los otros seres y con los objetos, en la interacción con la realidad. El mismo autor considera que la formación sucede únicamente mediante una actividad reflexiva, que distingue de la actividad reflectante. La actividad reflectante sirve para reproducir lo existente, en todo caso para discriminar y aplicar; remite a los procesos de transmisión de información, capacitación, adiestramiento o entrenamiento. Pero la formación es una actividad que requiere de la reflexión, que lleva a la transformación de lo existente, la innovación, la creación, la crítica y la resignificación. Desde esta idea, solo hay formación cuando se reflexiona, y con ello se transforma el mundo y la cultura en el que una persona se desenvuelve. Se transforma a sí misma en sus prácticas, sus acciones, sus significados, su habla; y con ello transforma el entorno, la cultura.

Para que ello suceda, Honoré (1980) coincide con Ferry (1990) en que la formación no se puede dar sino como un proyecto de transformación personal: "formarse no puede ser más que un trabajo sobre sí mismo, libremente imaginado, deseado y perseguido, realizado a través de los medios que se ofrecen o que uno mismo se procura" (Ferry, 1990, p. 43). Y todo eso empieza con el reconocimiento de ser parte de aquello en lo que uno o una se forma, en este caso, reconocerse a sí 
como docente de determinada institución. Producto de este reconocimiento o asunción se generan necesidades formativas; el personal docente se da cuenta de que necesita mejorar sus habilidades, destrezas y conocimientos. En este proceso cuestiona también su entorno: las prácticas cotidianas de sus colegas y las propias, las exigencias institucionales y aquello que le es brindado en los procesos de capacitación o actualización docente. Para que esto suceda, la persona debe significar la docencia como algo más que un trabajo, como un elemento primordial para su vida.

Con estas ideas, la formación docente equivale a la apropiación de la cultura docente, pero también lleva a su transformación. No implica solo dar clases en una institución, tampoco se trata de repetir y aplicar lo que otros sujetos hacen o lo que al propio personal docente se le ha enseñado o exigido hacer. Formarse como docente quiere decir que la persona ha asumido como proyecto personal el ser docente y que reflexiona al respecto para transformarse a sí misma como profesora, confrontando sus viejas prácticas, las prácticas e ideas aceptadas, incluso las exigencias institucionales, para mejorarse a sí misma en su rol docente y con ello transformar la cultura docente en la que se encuentra inserta.

Vaillant y Marcelo (2015) proponen que la formación de docentes se da en 4 etapas: los antecedentes, la base, el comienzo y el desarrollo. Las primeras dos etapas suceden antes de la incorporación al puesto de trabajo, ahí se desarrollan ideas y significados que orientan las prácticas del profesorado no solo en sus inicios en dicha labor, sino de manera más permanente; estas etapas se relacionan con la historia de vida de cada sujeto, sus experiencias escolares, la concepción que le da a la enseñanza, su experiencia profesional y académica, entre otros elementos. La etapa de "el comienzo" refiere a la formación que sucede una vez que se incorporan a las labores docentes en alguna institución, destaca aquí la figura de los mentores o mentoras, que son docentes de mayor experiencia que acompañan y aconsejan a quienes apenas inician. Finalmente, el desarrollo refiere a la formación continua con base en las necesidades que se presenten en el profesorado, ya sea de manera autodidacta o mediante procesos de capacitación o escolarización. En todas las etapas, destacan los autores, es primordial mantener una mentalidad y práctica reflexiva y una actitud de apertura permanente al cambio y la transformación.

Para esta investigación se retoman las tres primeras etapas propuestas por Vaillant y Marcelo (2015), ya que es ahí donde se encuentran las bases del significado que el profesorado le da a la docencia. Cabe aclarar que estas bases no determinan de manera absoluta la trayectoria docente, pero sí la orientan. En el siguiente apartado se discute en torno al concepto de significado y cómo se vincula con los procesos formativos.

\section{Significado y formación}

En el punto anterior se discutió acerca de la relación existente entre los conceptos de formación y cultura. Geertz (1987) es un autor obligado al considerar el concepto 
doi: http://doi.org/10.15359/ree.24-1.14

URL: http://www.una.ac.cr/educare

CORREO: educare@una.cr

de cultura, plantea que esta "consiste en estructuras de significación socialmente establecidas en virtud de las cuales la gente hace cosas... y se adhiere a éstas" (p. 26). Con estas palabras se entiende que los actos humanos, las palabras, las conductas, los sentimientos, toda acción y creación humana responden a un orden simbólico, tienen significados. En este entendido, la cultura es un complejo tejido de significados construidos en sociedad respecto a los diversos objetos sociales.

Para la definición del concepto de significado, por su parte, me remitiré a la teoría del interaccionismo simbólico, específicamente basado en las ideas de Blumer (1982), quien plantea que las personas actúan en la vida cotidiana en función de los significados que le dan a los objetos; el significado es una orientación para la acción. Los significados se construyen, desde esta perspectiva, a partir de la interacción que tienen las personas entre sí y con los objetos y no son estáticos, sino que se pueden modificar en función de la interpretación de las situaciones, circunstancias y contextos particulares en las que se encuentren los sujetos. Por ejemplo, el significado que el profesorado de la FES Iztacala le da a la docencia se construye en función de las interacciones y experiencias que tienen y han tenido con miembros de la comunidad escolar al ejercer su rol docente; pero también se relaciona con sus propias experiencias y los ambientes donde se han desenvuelto en etapas previas a su incorporación como docentes en esta institución. Además, ese significado puede cambiar en función de situaciones particulares que enfrenten en su vida cotidiana.

En este sentido, el significado que este profesorado le da a la docencia se relaciona con la cultura en donde se encuentra inserto. En este artículo hablo específicamente de cultura docente y para ello me remito a Pérez (1998), quien considera toda escuela como un cruce de culturas; dice que la escuela es un espacio de intercambio y transacciones simbólicas que se convierte en el marco de construcción de las significaciones de los individuos. Este autor habla, así, de una cultura escolar; pero en esta investigación el foco está puesto en el personal docente, por ello aquí me refiero más bien a una cultura docente, la cual se puede entender como el entramado de significados que el mismo sujeto docente construye en torno a la práctica docente a partir de diversos procesos de interacción en determinado contexto institucional.

La cultura docente refiere a la forma de ser, actuar y significar la docencia por parte del mismo profesorado, dicha cultura se construye en el proceso de ser docente, en la vida cotidiana; no se restringe solo al terreno de un aula de clases, ni surge exclusivamente de la escolaridad o capacitación que haya recibido en temas relativos a la pedagogía o la docencia, sino que implica una serie de interacciones con diversos actores, objetos y situaciones del entorno social en el que el profesorado se desenvuelve cotidianamente (Lozano-González, 2018). 
En la vida cotidiana escolar, el profesorado paulatinamente adquiere la cultura docente propia de la institución en la que se encuentre, se adscribe a las prácticas institucionalizadas, actúa de manera similar a la de sus colegas. Pero no por ello dejan de ser sujetos individuales, sus acciones como docentes no carecen de una dimensión personal y las experiencias que tienen diariamente son propias de cada persona docente. Son capaces de interpretar las circunstancias particulares en las que se encuentran y reflexionar respecto a su propia labor y, con ello, cambiar sus significados y actuaciones respecto a la docencia.

Es en este juego entre lo público y lo privado, entre lo institucional y lo personal, entre lo intersubjetivo y lo subjetivo, entre lo impuesto y lo construido, entre lo instituido y lo instituyente donde el profesorado crea significados respecto a su propia labor, respecto a la docencia. De esta manera, analizar los significados que el profesorado del área de la salud y la manera en que los ha construido implica estudiar también su proceso formativo como docentes. En este artículo se hace particular énfasis en los inicios en la docencia.

\section{Proceso metodológico}

Geertz (1987) menciona que el análisis de la cultura ha de ser"no una ciencia experimental en busca de leyes, sino una ciencia interpretativa en busca de significaciones" (p. 20), en este sentido, la presente investigación parte de una orientación interpretativa, es decir, de corte cualitativo. La investigación cualitativa busca acceder a los significados que yacen detrás de las acciones humanas convertidas en discursos (Álvarez-Gayou, 2003; Taylor y Bogdan, 1990). La persona investigadora cualitativa se encarga de reunir información de diversos medios (entrevistas, observaciones, cuestionarios) y los convierte en textos, los cuales son interpretados en función del contexto en que estos fueron obtenidos y el marco teórico interpretativo construido para cada investigación.

En el caso de esta investigación, el contexto es la FES Iztacala, escenario que fue descrito al inicio del artículo; el marco teórico interpretativo se sustenta en el concepto de formación docente y su relación con los conceptos de cultura y significado. Por su parte, el discurso que es sujeto a análisis e interpretación surge de las respuestas que docentes de diversas carreras de la FES Iztacala otorgaron a un cuestionario que, enseguida, será descrito.

La recolección de la información la realicé en el mes de enero del año 2018, las personas informantes son parte del profesorado de la FES Iztacala que asistieron a un curso impartido dentro del Programa de Superación Académica Permanente (PROSAP) de la FES Iztacala titulado Investigación y Transformación de la Práctica Docente. El curso se ofertó al profesorado de todas las carreras y la inscripción a este fue de carácter voluntario. En el marco del curso, los sujetos asistentes respondieron a un cuestionario de 2 preguntas: ¿qué significa para mí ser profesor o profesora? y ¿cómo llegué a ser profesor o profesora? Dichas preguntas fueron formuladas 
doi: http://doi.org/10.15359/ree.24-1.14

URL: http://www.una.ac.cr/educare

CORREO: educare@una.cr

con la intención de obtener información que permitiera interpretar cómo el significado que le dan a la docencia se vincula con su proceso de formación docente, en particular sus inicios en la docencia. Se solicitó al profesorado brindar respuestas amplias, sin límite de palabras y de tipo narrativo; la redacción la hicieron en los espacios y con los tiempos que cada quien juzgara convenientes, con un plazo de un día para su entrega. Se obtuvieron resultados satisfactorios y, por ello, se juzgó que las dos preguntas formuladas eran suficientes. También se mencionó que dichas respuestas serían usadas para esta investigación y se garantizó el anonimato. Todo el grupo inscrito en el curso aceptó participar en el cuestionario.

En total 38 personas contestaron el cuestionario, se dividen de la siguiente manera: 28 mujeres y 10 hombres; 25 de la licenciatura en Enfermería (Enf), 4 de Psicología (Psic), 4 de Cirujano Dentista (Dent), y 3 de Biología (Bio) y 2 de Médico Cirujano (Med). Para la presentación de los testimonios en este documento diseñé un código de identificación que se compone de la siguiente manera: número de cuestionario -carrera de adscripción- antigüedad en la UNAM. Ejemplo: C6-Enf-35.

Una vez contestados los cuestionarios procedí con su transcripción, lo que permitió su análisis y categorización. Decidí centrarme inicialmente en la pregunta relativa al significado de la docencia para obtener categorías analíticas a partir de las respuestas. Obtuve de este proceso 3 grandes categorías de análisis en relación con el significado de la docencia:

1. Una referida a la acción de la persona docente en relación con la formación o profesionalización de sus estudiantes.

2. La segunda refiere al compromiso y responsabilidad que implica desempeñarse como profesor o profesora.

3. Otra remite al sentimiento de honor, satisfacción y orgullo que manifiesta el profesorado respecto a su labor docente.

Cabe aclarar que en algunas respuestas del profesorado encontré indicios de más de una categoría, por ejemplo: mencionar que es un orgullo formar a las nuevas generaciones de alumnos y alumnas; en este caso hay referencia a la primera y tercera categorías, por ello no son categorías de carácter excluyente.

Posteriormente tomé las respuestas de cada una de las categorías analíticas antes mencionadas y las crucé con las respuestas obtenidas a la otra pregunta, referida a la trayectoria docente y los inicios en dicha labor del profesorado que contestó el cuestionario. De esta forma es posible analizar la relación existente entre el significado que le dan a la docencia y su proceso de formación docente. 
Por otra parte, es importante mencionar que el proyecto de investigación del cual se deriva este artículo lleva ya varios meses de trabajo, en este tiempo me he dedicado también a la observación de la vida cotidiana en la FES Iztacala, a dialogar con autoridades escolares y estudiantes, he entrevistado a docentes de todas las carreras, además de analizar los planes de estudio de las distintas carreras. En este artículo también habrá indicios de estas pesquisas, pero tomando como base los cuestionarios antes mencionados.

\section{Resultados y análisis}

Como docente... te conviertes en un guiador o facilitador del conocimiento

De las 38 personas que contestaron el cuestionario, 25 de ellas relacionan la docencia con el proceso de formación o profesionalización de estudiantes, consideran que con sus acciones como docentes contribuyen en mayor o menor medida en dicho proceso. Las siguientes respuestas permiten ejemplificar lo anterior:

Significa poder contribuir a la profesionalización de los alumnos durante su formación como enfermeros. (C1-Enf-10)

Participar en la formación y desarrollo de habilidades de una persona. (C8-Enf-29)

Un acompañante en el aprendizaje de los alumnos actuando como facilitador del mismo. (C18-Dent-37)

En los testimonios anteriores se observa una tendencia a significar el trabajo docente como una piedra angular en la formación académica de sus estudiantes, en este caso futuras generaciones profesionales en el área de la salud. El uso de palabras como contribuir, orientar y facilitar remite directamente a las teorías constructivistas, que es el modelo teórico predominante y mayormente aceptado actualmente. Esto se puede observar más claramente en los siguientes testimonios:

Ser un personaje muy importante en la labor de aprendizaje de los estudiantes, pero no responsable al 100\% porque ahí intervienen muchos factores. (C32-Med-30)

Mi granito de arena es parte de la formación de una persona que en el futuro atienda a los pacientes... No significa que el alumno deba reproducir la información que le brindo, tampoco debe estar $100 \%$ atento a lo que digo por miedo o autoridad, al contrario, me gusta que sientan confianza. Mi función es apoyarlos para que terminen la carrera de forma satisfactoria, enamorados de ella y con aprendizaje significativo. (C29-Enf-5)

El construir el conocimiento es una responsabilidad que uno tiene con cada alumno. (19-Psic-2) 
doi: http://doi.org/10.15359/ree.24-1.14

URL: http://www.una.ac.cr/educare

CORREO: educare@una.cr

En las palabras anteriores se reconoce que la labor del personal docente tiene ciertas limitaciones, que el conocimiento se construye por parte del estudiantado en la interacción con su entorno y los distintos actores con que convive, entre ellos sus profesores y profesoras. Los testimonios permiten ver que los planteamientos de las teorías constructivistas se han interiorizado en su forma de pensar y actuar. Y realmente esto es algo que se debería esperar, pues como el mismo grupo docente menciona, se ha formado en gran medida a través de cursos, diplomados o posgrados relacionados con temas de docencia, la mayoría de las veces ofertados por la misma institución en la que laboran: la FES Iztacala.

Cabe mencionar que el modelo pedagógico aceptado, fomentado e, incluso, exigido por la institución es el constructivismo, específicamente es muy retomada la teoría del aprendizaje significativo de David Ausubel. Los planes de estudio actuales están diseñados sobre esas bases teóricas y la oferta de actualización en docencia generalmente adopta esa posición. El constructivismo está presente en el ambiente cotidiano de la FES Iztacala, es lógico que el profesorado adopte algunas de sus ideas.

Lo anterior es resultado de las recientes modificaciones a los planes de estudio y los modelos educativos en la FES Iztacala, donde predomina el discurso constructivista que exige que el profesorado desarrolle un pensamiento crítico y mantenga una práctica reflexiva. Esto no es exclusivo de la FES Iztacala, más bien es una tendencia generalizada. Realicé una búsqueda de artículos recientes que tomaran por objeto las prácticas docentes o los procesos de formación de profesorado en el área de la salud en América Latina y encontré que el profesorado que ha recibido capacitación y entrenamiento en la docencia menciona que a partir de ello transforma y mejora sus prácticas.

Sin embargo, de acuerdo con los estudios consultados, una deficiencia es el poco desarrollo del pensamiento crítico, pues se toma la pedagogía como un cúmulo de información, técnicas y actividades que deben ser aplicadas a manera de receta (Benavides-Caballero, InsfránSánchez y Viniegra-Velázquez, 2006; Costa, 2010; Díaz, Aguilar, Viniegra, Toribio y Hernández, 2004; Henao-Castaño, Nuñez-Rodríguez y Quimbayo-Díaz, 2010; Pinilla, 2011; Sáenz-Losada, Cárdenas-Muñoz y Rojas-Soto, 2010; Sebold y Carraro, 2011).

De esta manera, el profesorado asume un modelo constructivista de enseñanza en sus clases, pero más por exigencia de las autoridades escolares y los lineamientos curriculares que por un genuino convencimiento de su pertinencia, incluso en la bibliografía se menciona que existen ciertos malentendidos o interpretaciones erróneas de lo que significa ser "docente constructivista". Esto lo he corroborado en la observación de la vida cotidiana en la FES Iztacala, específicamente a partir de diálogos que he tenido con estudiantes de diversas carreras, quienes mencionan, a manera de queja, que una parte de sus docentes entiende el constructivismo como dejar que el estudiantado investigue los temas y los exponga en clase, argumentando que es su responsabilidad construir el conocimiento. 
En ocasiones, la actuación del profesorado se restringe a la reproducción de modelos considerados válidos, como el constructivista actualmente, o la repetición de las prácticas con las que sus generaciones fueron formadas. Cuando el profesorado se inicia en su labor de enseñanza se inserta en un contexto ya instituido, donde predominan ciertas prácticas y existen ciertas normas implícitas o explicitas que guían su comportamiento, se inserta en una cultura preconstruida. Al respecto, Pérez (1998) plantea:

Las culturas funcionan como patrones de intercambio precisamente porque forman una coherente red de significados compartidos que los individuos generalmente no cuestionan y se admiten como marcos útiles y presentes en los procesos de comunicación. Los significados se objetivan en comportamientos, artefactos y rituales que forman la piel del contexto institucional y que se asumen como imprescindibles e incuestionables por su carácter previo a la intervención de los agentes. (p. 16)

Es lógico que docentes noveles, sin conocimiento amplio respecto a la pedagogía, la docencia - la didáctica, repliquen aquellas prácticas que les son exigidas y enseñadas en sus primeros momentos. Por ejemplo, en años recientes, a todos los profesores y las profesoras que se incorporan a la UNAM se les exige como requisito para su contratación tomar un curso que lleva por nombre Inducción y formación docente para profesores de nuevo ingreso y reingreso, en él se discuten, entre otros temas, el modelo constructivista como un elemento clave para el desarrollo de las clases.

A partir deestetipo de cursos (queademás son obligatorios) y en lainteracción cotidiana entre colegas y autoridades, el profesorado adopta el modelo constructivista, se apropia de su discurso y de sus conceptos. Sin embargo, a la luz de los testimonios recopilados en esta investigación, aún prevalecen ideas propias de la educación tradicional, donde el personal docente se asume a sí mismo como el sabio portador del conocimiento y responsable de su transmisión.

Significa que lo poco o mucho que sé, lo pueda dejar a alguien más, considero que el conocimiento sin transmisión no sirve. (C32-Bio-10)

La oportunidad de transmitir conocimientos específicos en el área de enfermería, compartir experiencias en el ámbito laboral y personal, considerando la juventud de los alumnos. (C25-Enf-15)

\section{Para muchos alumnos el profesor significa un modelo a imitar. (C22-Dent-38)}

Aquíse observa que un grupo de docentes seasumea símismo como personas experimentadas y el estudiantado es visto como personas carentes de experiencia, debido a su juventud. Por ello, la labor del profesorado es transmitir sus conocimientos y experiencia al alumnado. Un claro resabio de la educación tradicional, en la que muchas de las profesoras y profesores que contestaron el cuestionario recibieron formación, de acuerdo con sus propias palabras: 
doi: http://doi.org/10.15359/ree.24-1.14

URL: http://www.una.ac.cr/educare

CORREO: educare@una.cr

Por el tipo de educación que llevé desde la infancia hasta la Universidad solo conocíel sistema tradicionalista, hasta hace algunos años que empezaron a cambiar las tendencias. En los últimos años he mejorado mucho, busco otras formas de dar mi clase, más interactiva. Mi propósito es seguir mejorando y prepararme más. (C28-Enf-19)

Las trayectorias del profesorado que brindó su testimonio para esta investigación son muy variadas, así como sus inicios en la labor docente; sin embargo, para esta categoría analítica, donde el significado que le dan a la docencia reside en su labor sobre sus estudiantes, predominan aquellas personas que dicen haber iniciado en la docencia por casualidad o por invitación de algún colega:

Soy enfermera de vocación, luego de 10 años de trabajar en hospitales realicéotras actividades y tomé cursos de otras cosas. Un día una compañera me invitó a llevar mis documentos porque requerían profesores y yo cubría el perfil. Necesitaba dinero y lo hice. Inicié sin ninguna preparación para dar clases, estudiaba y preparaba material didáctico sin encontrarle sentido a lo que hacía. (C28-Enf-19)

Luego de 10 años de descanso y 15 años de experiencia clínica en la Secretaría de Salud me surge la inquietud de regresar a laborar. Por recomendación de mi esposo llevo mi CV a la FES Iztacala, recibí una llamada preguntando por la Lic. Josefina, me tomó por sorpresa pues hacía tanto tiempo que solo me decían mamá de Eduardo y Liliana, la esposa de... Ileguéa la entrevista nerviosa y con incertidumbre. Me señalaron que tomaría el grupo ;al día siguiente! (C25-Enf-15)

Aún no puedo creer que sea docente, llevo muy poco tiempo, además que no estudié para dar clases, agregando la edad que tengo. Inicié por invitación de una profesora que vio en mí capacidades para ello. (C34-Psic-1)

Cuando se inicia en la labor docente de esta manera, es en el mismo acto de enseñar donde el profesorado se forma, aprendiendo de la experiencia; o bien tomando cursos, diplomados o incluso posgrados. Algunos testimonios mencionan que iniciaron sin preparación alguna para ser docentes y consideraron necesario capacitarse y actualizarse constantemente por un sentido de responsabilidad y compromiso con la labor docente. Esto da pie a la siguiente categoría analítica.

Ser docente es... un gran compromiso para conmigo y con la profesión

En esta categoría analítica ubiqué aquellos testimonios en donde se relaciona la docencia con la responsabilidad y el compromiso, lo que lleva directamente a una necesidad de capacitación y constante actualización en el terreno de la docencia, la didáctica y la pedagogía en general. Del total de testimonios obtenidos, en 16 de ellos se encuentran indicios de esta categoría: 
doi: http://doi.org/10.15359/ree.24-1.14

URL: http://www.una.ac.cr/educare

CORREO: educare@una.cr

Un compromiso ya que estamos involucrados en un proceso que es importante para el futuro profesional de nuestros alumnos... es renovarse constantemente, la docencia te induce a estar constantemente actualizado. Es un reto constante ya que cada semestre enfrentas grupos humanos con necesidades y características diferentes y tienes que ser su líder. (C33-Med-12)

Significa mucho, desde un aspecto profesional significa asunción, no tengo mucho como profesora pero comienzo a asumirme como tal. Me asumo como responsable del proceso de enseñanza y aprendizaje y de lo que se transmita en dicho proceso. También como parte de una institución que tiene calidad y expectativas de que yo mantenga esa calidad. Me asumo como persona con un compromiso propio de ser mejor cada día, de mejorar mi trabajo porque me gusta y lo disfruto. (C30-Enf-2)

De acuerdo con el diccionario de la Real Académica Española la palabra compromiso significa "obligación contraída", lo que quiere decir que una persona no tenía cierta obligación, pero por ciertas circunstancias la adquiere. Cabe aclarar que todo el profesorado que brindó su testimonio para esta investigación pertenece al área de la salud y la biología, los estudios de licenciatura de estas personas son en la misma área y, por lo mismo, no recibieron preparación inicialmente para desempeñarse en un aula de clases.

La mayoría de las personas egresadas de las carreras en el área de la salud (Enfermería, Médico Cirujano, Cirujano Dentista y Psicología) pretenden ejercer su profesión en las áreas específicas para las que se prepararon, pocas son los que piensan que podrían en algún momento trabajar como docentes; más bien se orientan al trabajo clínico, como se menciona en los siguientes testimonios:

Mi jefa de área que es quien me ha apoyado en muchos sentidos, ella me decía algunos consejos o actividades que podía implementar si llegaba a ser docente. Pero prácticamente en psicología lo que más nos encausan es a lo clínico, al menos en mi generación, siempre enfocados en cuanto a los pacientes y recursos humanos. (C34-Psic-1)

No era mi plan entrar aquí, antes de la docencia mi plan era trabajar de lleno en la enfermería, lamentablemente no tuve un profesor que me dijera: la enfermería no es solamente estar en un hospital, sino que también se trata de administración, investigación y docencia. A pesar de que esto sí está en nuestro perfil de egreso, en el perfil profesional, pero no hubo nadie que me dijera todo lo que podía hacer. (C11-Enf-5)

(Durante la licenciatura...) nadie nos menciona que podemos llegar a ser docentes, la mayoría de profesores nos menciona que el dinero está en el consultorio. (C36-Dent-13) 
doi: http://doi.org/10.15359/ree.24-1.14

URL: http://www.una.ac.cr/educare

CORREO: educare@una.cr

Debido a lo mencionado en los anteriores testimonios, me di a la tarea de analizar los planes de estudio de las carreras que se imparten en la FES Iztacala, toda esta información está disponible en la página web oficial de la Facultad (FESI, UNAM, 2019). Encontré que en el perfil de egreso de la carrera de Cirujano Dentista la única mención a un posible rol docente es cuando se dice que el futuro egresado podría desempeñarse en labores de prevención y promoción de la salud bucal, en su plan de estudios no tienen ninguna materia enfocada en temas de docencia; lo mismo sucede en la carrera de Optometría. En Médico Cirujano, en el plan de estudios anterior al que entró en vigencia en el año 2016 se tenían dos módulos de pedagogía de carácter obligatorio, pero en el nuevo plan ya no existen, en su lugar se tiene, durante 4 semestres, el Seminario de Integración Sociopsicobiológica. En estas tres carreras es en donde, desde el currículo formal, la posibilidad de un trabajo como docente del alumnado egresado se plantea como algo lejano o incluso fuera de las posibilidades.

En la carrera de enfermería, como se dice en un testimonio anterior, sí se plantea el rol docente como una de las cuatro áreas de desempeño profesional del egresado de la licenciatura, para ello se imparte un módulo obligatorio llamado Educación en Enfermería. En Psicología, por su parte, dentro del perfil de egreso se plantea que el estudiantado desarrolle competencias pedagógicas y se mencionan como posibles campos laborales las escuelas de cualquier nivel y procesos de capacitación o adiestramiento; además, son varias las materias que se cursan enfocadas en cuestiones educativas. Sin embargo, como se vio en los testimonios, ser profesor o profesora no es algo que figure dentro de los planes de estudiantes de estas carreras.

En Biología se ofrecen las materias optativas llamadas Didáctica de la biología y Educación ambiental sustentable, se menciona también que un posible campo laboral es la educación. El perfil de egreso de esta carrera no se orienta claramente a la docencia, sino más bien a la investigación, pero en función de los testimonios que recopilé para esta investigación, pareciera que en esta carrera el perfil de sus estudiantes sí tiende a la docencia:

En la universidad me metí de lleno al laboratorio y me encantó la investigación, pero nunca quité el dedo del renglón de que iba a ser maestra de la FESI. Además di clases en secundaria; pero no me gustó porque el $80 \%$ del tiempo era estar callándolos; también di clases de regularización a personas incluso mayores que yo, y en la empresa Bimbo en capacitación. (C32-Bio-10)

Estaba indeciso sobre ser biólogo o maestro, un profesor de la secundaria me recomendó estudiar la carrera que deseaba y ejercer como maestro. (C21-Bio-20)

A fin de cuentas, lo que todo este profesorado de la FES Iztacala tiene en común es la poca o nula preparación para desempeñarse como docentes una vez que inician con esta labor. Diversos testimonios manifestaron haber sentido nerviosismo e incluso cierta angustia 
en sus primeras experiencias como docentes; sin embargo, esos sentimientos se acompañaron también de satisfacciones y alegrías. Esta combinación de emociones les lleva a sentir un fuerte compromiso con la labor docente. Los siguientes testimonios corroboran las ideas anteriores:

Sentía la necesidad de formarme en el área, me sentía bien desempeñando el papel, pero necesitaba adquirir habilidades en el área. (C25-Enf-15)

Con los añosmehe dado cuenta de queserdocenteno esuntrabajo sencillo, necesitaspreparación constante y estar verdaderamente comprometido para ver resultados en la formación de los futuros profesionales. Se ha convertido en parte de mi estilo de vida. (C11-Enf-5)

Tuve la fortuna de ser invitada hace 5 años. Antes trabajaba en hospital y no me gustaba la docencia porque mis padres son docentes. No quería pasar toda la vida en una escuela. En mis inicios me tocó trabajar el primer día sin temario ni nada de carpeta docente. La profesora con que me tocó me apoyó pero igual me exhibía cada que podía, eso me estresaba mucho. Considero que he ido creciendo, y he aprendido a trabajar con otros docentes. Continuo estudiando para actualizarme en mi profesión y también en el área docente, estoy por concluir la maestría en educación. (C29-Enf-5)

Iniciar en una labor profesional que no se domina genera angustia, el profesorado novel del área de salud entra en un terreno desconocido, está fuera de su zona de confort. Esto, dice Honoré (1980), es un fuerte impulso hacía la formación, entendida como un proyecto de transformación individual, intencionado y dirigido; "la formación se promueve porque hay angustia. La angustia usualmente lleva a la reflexión, a la elaboración de un proyecto, a la esperanza, a la intencionalidad, y esta, a la acción" (Lozano-Andrade, 2017, p. 126). El estado contrario a la angustia, el del confort o la tranquilidad, conduce más bien a la estabilidad, a situaciones donde domina el pensamiento no reflexivo o reflectante.

En los testimonios anteriores se observa que ser docente es significado como algo que requiere compromiso, responsabilidad y constante preparación para lograr dicha labor con éxito; esta necesidad de capacitarse y actualizarse surge, en gran medida, de la inexperiencia y de darse cuenta de que sus conocimientos en el área que enseñan no son suficientes, sino que requieren también la parte pedagógica y didáctica. Para ello gran cantidad de docentes decide integrarse a cursos, talleres, diplomados o posgrados en el área de la pedagogía, donde espera adquirir los conocimientos y habilidades que percibe como necesarios. Con esto se corre el riesgo de que se apropie de los discursos que se promueven en estos espacios; discursos institucionalizados y prácticas exigidas (como el constructivismo y los malentendidos que acarrea, como se discutió en el apartado anterior), que se asimilan de manera irreflexiva, como una actividad reflectante. 
doi: http://doi.org/10.15359/ree.24-1.14

URL: http://www.una.ac.cr/educare

CORREO: educare@una.cr

Lozano-Andrade (2014) remite a Honoré y menciona que "el pensamiento y sus formas simbólicas son una construcción social que genera una sensación de estabilidad" (p. 10), aquí coincide con Pérez (1998) en que las culturas son formas simbólicas que difícilmente son cuestionadas debido a su carácter pre-existente y su aparente funcionalidad para la vida cotidiana. Nuevamente se llega a una zona de confort donde no hay formación.

La cultura docente preexistente incita al profesorado a asimilar y admitir para sí mismo las exigencias institucionales y los discursos oficialistas. La institución exige que el personal docente se forme y para comprobarlo exige certificados, premia a quien cumple con esto, y castiga a quien no. Así, la institución impulsa al profesorado a buscar, por todos los medios, constancias que acrediten su formación; aunque esto no es, en sentido estricto, formación, sino capacitación o entrenamiento. El personal docente llega a lo que he denominado una cultura docente de la certificación que está dirigida por los intereses y los discursos que permean el mercado de la formación (Lozano-González, 2018).

En el escenario anterior existe capacitación, entrenamiento y actualización; pero no necesariamente formación, al menos no en el sentido que en este artículo se entiende. La formación iniciaría cuando el profesorado comience a cuestionar su actuación y transformar su práctica cotidiana mediante procesos de pensamiento reflexivo y crítico. Cuando se debata el tejido de discursos, significados y prácticas que existe respecto a la práctica docente en la institución donde labora. Cuando se asuma la formación docente como un proyecto individual, libremente deseado y perseguido, más allá de la certificación.

Lo anterior implica, necesariamente, compromiso y responsabilidad con la docencia, el objeto de análisis en esta segunda categoría; pero se relaciona también con la primera categoría analítica, referida a la formación del alumnado; el profesorado siente compromiso y responsabilidad, pues sobre este recae la acción de enseñanza a las nuevas generaciones de estudiantado universitario, y aún más en la UNAM, una institución de prestigio y alto nivel académico. Todo esto puede resultar en angustia en ciertos momentos, pero también llega a ser algo satisfactorio, y esto da pie a la siguiente categoría.

Ser docente... es un orgullo, hago algo que amo.

En esa última categoría caen los testimonios que asocian la docencia con una labor satisfactoria, que produce orgullo y honor. En esta categoría entran 17 de los 38 testimonios recopilados. El orgullo, de acuerdo con el Diccionario de la Real Academia Española, es un sentimiento de satisfacción que surge de los logros, capacidades o méritos propios o por algo en lo que una persona se siente concernida. Algunos testimonios son los siguientes: 
Es un orgullo, hago algo que amo, me siento comprometida. (C26-Enf-9)

Soy afortunado de ejercer las dos cosas que me apasionan, ser profesor en la carrera de biología. Me encanta ser docente. (C21-Bio-20)

Hay varias razones por las que los docentes y las docentes que proporcionaron su testimonio significan la docencia como una actividad que produce orgullo, como un honor o un privilegio; una de ellas es por el prestigio con el que se asocia ser docente de nivel superior y más aún de la UNAM:

Me gusta ser docente en la UNAM, me llena de orgullo y más porque sien el hospital se enteran de que eres docente en la UNAM y no saben algo se acercan mucho a ti para que les des clase. (C37-Enf-2)

Una suerte y privilegio muy grandes de trabajar en algo que te gusta y es reconocido, te da un prestigio profesional. (C22-Dent-38)

La UNAM es la universidad más grande de México, durante el ciclo escolar 2017-2018 tuvo más de 349 mil estudiantes en su matrícula, de los cuales 204191 corresponden al nivel de licenciatura inscritos o inscritas en las 123 carreras que se ofertan; además, para la UNAM laboran más de 40 mil personas académicas (UNAM, Portal de Estadística Universitaria, 2019). En adición a la magnitud de esta universidad, de acuerdo con el ranking QS World University Rankings (2019), la UNAM es la mejor universidad de México y la segunda mejor de Iberoamérica, solo por debajo de la Universidad de Buenos Aires y por encima de todas las españolas, a nivel mundial ocupa el puesto 113 (QS World University Rankings, 2019). El personal docente de la FES Iztacala refiere constantemente que trabajar en la UNAM es causa de orgullo y es bien visto en otros espacios laborales, como los hospitales.

Sin embargo el ser docente no siempre es percibido como un orgullo; en diversos artículos que tratan el tema de la docencia en el área de la salud se menciona que esta labor en ocasiones es percibida como una profesión secundaria, por lo que se propone rescatar y valorizar la profesión docente en miras a mejorar las prácticas del profesorado universitario en el área de la salud. Así, surge la necesidad de una profesionalización docente al profesorado del área de la salud para que domine las cuestiones relativas a la educación, la enseñanza, la didáctica, la pedagogía y la epistemología de la educación, al igual que domina los contenidos que pertenecen al área de la salud (Henao et al., 2010; Pinilla, 2011; Sáenz-Losada et al., 2010; Sebold y Carraro, 2011). Esta idea es confirmada en algunos de los testimonios recopilados para esta investigación: 
doi: http://doi.org/10.15359/ree.24-1.14

URL: http://www.una.ac.cr/educare

CORREO: educare@una.cr

A diferencia de lo que nos dicen en el diplomado de que a mucha gente le da pena ser docente, a mí no me da pena... Dicen en el diplomado que es porque uno muchas veces no encuentra trabajo y es de lo único que encontraste, ese no es mi caso... (C37-Enf-2)

Son varios los casos de quienes brindaron su testimonio para esta investigación que comenzaron a trabajar en esta labor por necesidad económica, por invitación de colegas, como una actividad complementaria a su práctica clínica o para ocupar el tiempo libre después de su retiro. No son personas que desearan este trabajo, sin embargo, llega a ser tan satisfactorio que lo convierten en su modo de vida:

Por necesidad, ingresé a la UNAM durante la huelga de 1999, necesitaba trabajar ante la situación incierta y me integré al CONAFE, di clases de primaría multinivel en una comunidad rural con demasiadas carencias, tuve grandes satisfacciones. En este trabajo me nació el amor por la docencia. Hay dos actividades que me apasionan, educar y cuidar. Decidí terminar la carrera para ser enfermera y ser docente a la vez, continúo en ambas con gran amor. (C26-Enf-9)

Por otra parte están aquellas personas que realmente demuestran una vocación por la docencia, que desde temprana edad desearon desempeñarse como docentes y lo buscaron de manera insistente hasta lograrlo, incluso dando clases en diversos niveles o espacios educativos:

Desde pequeña yo sí tenía la inquietud de la docencia...nunca quité el dedo del renglón de que iba a ser maestra de la FESI, me costó varios años y exámenes de oposición hasta que logré que me dieran unas horas. (C32-Bio-10)

Inicié dando clases de danza desde los 12 años. En 2009 comencé a trabajar en la Secretaría de Salud en capacitación a auxiliares de salud en las comunidades y dando talleres de salud. En 2011 buscó trabajo y llego a una universidad privada, ahí tuve muchos tropiezos, sin embargo aprendí a resolverlos. En 2013 ingreso a la FESI. (C35-Enf-6)

Desde que iba en sexto de primaria y durante los tres años de secundaria apoyaba a mis compañeros en los temas complicados. Durante este tiempo fui reafirmando mi gusto por la biología. Durante el CCH me inscribí en el programa del INEA de alfabetización de adultos en una comunidad Ñañhu, fue una experiencia inolvidable. Ingresé luego a la ENEP Iztacala y cuando estaba haciendo mi tesis surgió la gran oportunidad. En ese entonces trabajaba dando clases de regularización y en una secundaria particular. (C21-Bio-20)

En casos como los anteriores se traza una trayectoria muy clara desde temprana edad. Se podría decir que son personas que nacieron para enseñar, y esa actividad la combinan con alguna otra que les genera igual pasión: la enfermería, la biología, la psicología, etc. Se trata de aquellas personas que se asumen docentes, así como se asumen trabajadoras de la salud o la biología: 
Yo soy biólogo, pero cuando alguien me pregunta ¿usted qué es? ¿a qué se dedica? Soy profesor en la universidad, esa es mi respuesta. Ya no soy biólogo, creo que ya lo dejé de ser, mi actividad ya es ser docente. La biología fue la disciplina en la que me formé, pero ahora mi actividad profesional es ser docente. (C38-Bio-28)

Esta categoría guarda relación con las dos primeras, el profesorado siente orgullo y satisfacción respecto a su labor de enseñanza, debido a la relación que mantiene con sus estudiantes, a la posibilidad de dejarles algo para su futuro profesional o personal. Esto, a su vez, se convierte en una responsabilidad y un compromiso consigo mico su propia persona, con sus estudiantes y con la institución en la que laboran.

\section{Conclusiones}

Los testimonios aquí presentados son producto, en primer lugar, de las experiencias, emociones y pensamientos propios de cada persona: la dimensión subjetiva. Al mismo tiempo surgen de la interacción de los sujetos en los contextos donde se han desenvuelto, como la escuela, el trabajo, la comunidad, etc.: la dimensión social. En el cruce de ambas dimensiones es en donde se producen los significados y se desarrollan las trayectorias formativas de este personal docente. Los testimonios presentados permiten ver la relación entre ambas dimensiones.

En la primera categoría analítica se observa que el personal docente significa su labor con base en el contacto e interacción con sus estudiantes; relacionan el ser docente con la formación o preparación profesional del alumnado; e incluso se expresan usando los términos y conceptos que la institución demanda al personal docente (el constructivismo). Es, hasta cierto punto, una manera de significar la docencia solo como un trabajo, la creación o modificación de cierto producto; ya sea el alumnado o el conocimiento. Aquí predomina la dimensión social y se desplaza la subjetiva.

En las otras dos categorías sucede lo contrario, ya sea que se asuma la docencia como una responsabilidad o un compromiso; o bien como un orgullo, un honor, algo que produce satisfacción. Todos estos significados se sustentan principalmente en la dimensión subjetiva; aunque exista relación con la social, pues la responsabilidad, el orgullo o la satisfacción pueden originarse de la relación del personal docente con el alumnado y la institución.

Cuando la docencia se significa principalmente a partir de la dimensión subjetiva, se produce una identificación con dicha labor, hay una asunción del sí mismo o misma como docente, se asume responsabilidad sobre el trayecto formativo. En el caso de informantes de esta investigación, se podría decir que dejan de ser profesionales de enfermería, medicina, odontología, psicología o biología que trabajan dando clases; se convierten en docentes. Quien trabaja como docente suele tomar cursos, diplomados o posgrados; es una exigencia 
doi: http://doi.org/10.15359/ree.24-1.14

URL: http://www.una.ac.cr/educare

CORREO: educare@una.cr

institucional; pero la formación no se limita a ello. Es cuando sucede la asunción de sí como docente cuando se inicia el auténtico trayecto formativo, como un proyecto deseado y perseguido, de transformación de la propia persona y de la cultura.

\section{Referencias}

Álvarez-Gayou, J. L. (2003). Cómo hacer investigación cualitativa. México: Paidós.

Benavides-Caballero, T. de J., Isafrán-Sánchez, M. D. y Viniegra-Velázquez, L. (2006). La evolución de la formación docente en el área de la salud. Revista Médica del IMMS, 44(2), 105-112. Recuperado de http://www.medigraphic.com/pdfs/imss/im-2006/im062c.pdf

Blumer, H. (1982). El interaccionismo simbólico: Perspectiva y método. Barcelona: Hora.

Costa, N. M. S. C. (2010). La formación pedagógica de profesores de medicina. Revista LatinoAmericana de Enfermagem, 18(1), 1-7. Recuperado de http://www.scielo.br/scielo. php?script=sci issuetoc\&pid=0104-116920100001\&lng=en\&nrm=iso

Díaz, A., Aguilar, E., Viniegra, L., Toribio, M. P.y Hernández, M. A. (2004). Formación de profesores para el área de la salud y epistemología de la educación. Revista Médica del IMMS, 42(4), 293-302. Recuperado de http://www.medigraphic.com/pdfs/imss/im-2004/im044d.pdf

Ducoing, P. y Fortoul, B. (Coords.). (2013). Procesos de formación (Vol. 1, 2002-2011, Colección Estados del Conocimiento). México: COMIE, ANUIES.

Facultad de Estudios Superiores Iztacala (FESI), Universidad Nacional Autónoma de México (UNAM). (2019). Recuperado de www.iztacala.unam.mx

Ferry, G. (1990). El trayecto de la formación: Los enseñantes entre la teoría y la práctica. México: Paidós.

Gadamer, H.-G. (2012). Verdad y método (Vol 1). Salamánca: Sígueme.

Geertz, C. (1987). La interpretación de las culturas. México: Gedisa.

Hegel, G. W. F. (1984). Propedéutica filosófica. México: UNAM.

Henao-Castaño, Á. M., Nuñez-Rodríguez, M. L. y Quimbayo-Díaz, J. H. (2010). El rol del profesional de la salud como docente universitario. Aquichan, 10(1),34-42. doi: https://doi.org/10.5294/ aqui.2010.10.1.4

Honoré, B. (1980). Para una teoría de la formación: Dinámica de la formatividad. Madrid: Narcea.

Lozano-Andrade, I. (2014). Debates y tensiones en torno a la formación docente: Notas para una sociología de la formación. Revista Actualidades Investigativas en Educación, 14(1), 1-20. 
doi: https://doi.org/10.15517/aie.v14i1.13382

Lozano-Andrade, I. (2017). Teoría y práctica en la formación docente. Una mirada sociológica. México: Newton.

Lozano-González, E. O. (2018). Teacher formation and teaching culture in everyday school life at university. The area of health case. The international journal of humanities education, 16(12), 33-43. doi: https://doi.org/10.18848/2327-0063/CGP/v16i01/33-43

Pérez, Á. I. (1998). La cultura escolar en la sociedad neoliberal. Madrid: Morata.

Pinilla, A. E. (2011). Modelos pedagógicos y formación de profesionales en el área de la salud. Acta médica Colombiana, 36(4), 204-218. doi: https://doi.org/10.36104/amc.2011.1451

QS World University Rankings. (2019). Who Rules? Recuperado de https://www.topuniversities. com/university-rankings/world-university-rankings/2019

Sáenz-Losada, M. I., Cárdenas-Muñoz, M. L. y Rojas-Soto, E. (2010). Efectos de la capacitación pedagógica en la práctica docente universitaria en salud. Revista de Salud Pública, 12(3), 425-433. doi: https://doi.org/10.1590/\$0124-00642010000300008

Sebold, L. F.y Carraro, T.E. (2011). La práctica pedagógica del docente en enfermería: Una revisión integradora de la literatura. Enfermería Global, 10(22). 1-11. doi: https://doi.org/10.4321/ $\underline{\text { S1695-61412011000200023 }}$

Taylor, S. J. y Bogdan, R. (1990). Introducción a los métodos cualitativos de investigación. Buenos Aires: Paidós.

Universidad Nacional Autónoma de México (UNAM). (2017). Cultura y formación docente en la Facultad de Estudios Superiores (FES) Iztacala (IA401317). México: Autor.

Universidad Nacional Autónoma de México (UNAM), Portal de Estadística Universitaria. (2019). La UNAM en números. Recuperado de http://www.estadistica.unam.mx/numeralia/

Vaillant, D. y Marcelo, C. (2015). El ABC y D de la formación docente. Madrid: Narcea.

Yurén, M. T. (1999). Formación, horizonte al quehacer académico (Reflexiones filosóficopedagógicas). México: UPN. 